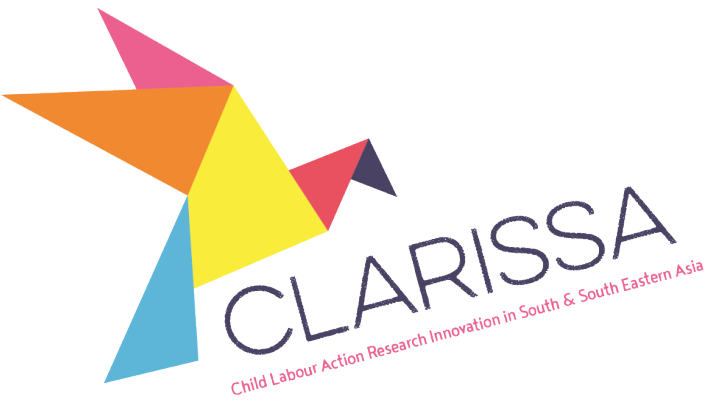

\title{
EXPOSING THE WORST FORMS OF CHILD LABOUR IN BANGLADESH'S LEATHER SECTOR
}

\begin{abstract}
As one of the country's biggest employers and its second largest exporter, the leather sector is big business in Bangladesh. But it is also in crisis. A dramatic decrease in the global demand for leather since COVID-19 has led to the collapse of the supply chain with workers, especially children, bearing the worst of the brunt. As cracks in the industry's surface widen, new research from the Child Labour: Action-Research-Innovation in South and South-Eastern Asia (CLARISSA) programme shines a light into its hidden corners, revealing examples of the worst forms of child labour (WFCL) at almost every turn.
\end{abstract}

\section{BACKGROUND}

Despite the raft of international and national measures to help combat it, child labour remains a widely accepted fact of life in Bangladesh. An estimated 3.45 million children engage in some form of work including 1.28 million children engaged in the WFCL. ${ }^{1}$ There are particular concerns about child labour in the leather industry, where children have been found undertaking hazardous work often without safety measures and where pay is low, and the hours are long. It is a situation made worse by a global pandemic that has further pushed leather production towards a domestic market and into an unregulated informal sector. Driven by economic hardship, many children and their families are faced with the stark choice to undertake dangerous work or simply starve.

\section{CHALLENGES AND OPPORTUNITIES}

Reducing the number of children engaging in the WFCL is far from straight forward. A difficult set of societal challenges are at play, including deeply ingrained social norms concerning child work and denial within the supply chain and among policy makers that it even exists. Yet there are opportunities for change. By gathering evidence and listening to children, their families and communities, CLARISSA is working to improve understanding of the factors that drive the WFCL within the leather industry and collaboratively create child-centred, innovative interventions that can help reduce the danger, exploitation and abuse children face.

${ }^{1}$ The National Child Labour Survey 2013

${ }^{2}$ The research in Bangladesh is led by the Terres des Hommes Foundation, Grambangla Unnayan Committee and ChildHope UK.

\section{THE EVIDENCE}

CLARISSA's research in Bangladesh ${ }^{2}$ has begun with a mapping exercise to observe the 'micro-steps' that make up the supply chain of the Bangladesh leather industry. The aim of the mapping is to gather evidence of the 'unseen' children working within and help build participatory research as an intervention. The mapping offers a high level of detail with which researchers can begin to analyse the full supply chain in relation to the WCFL.

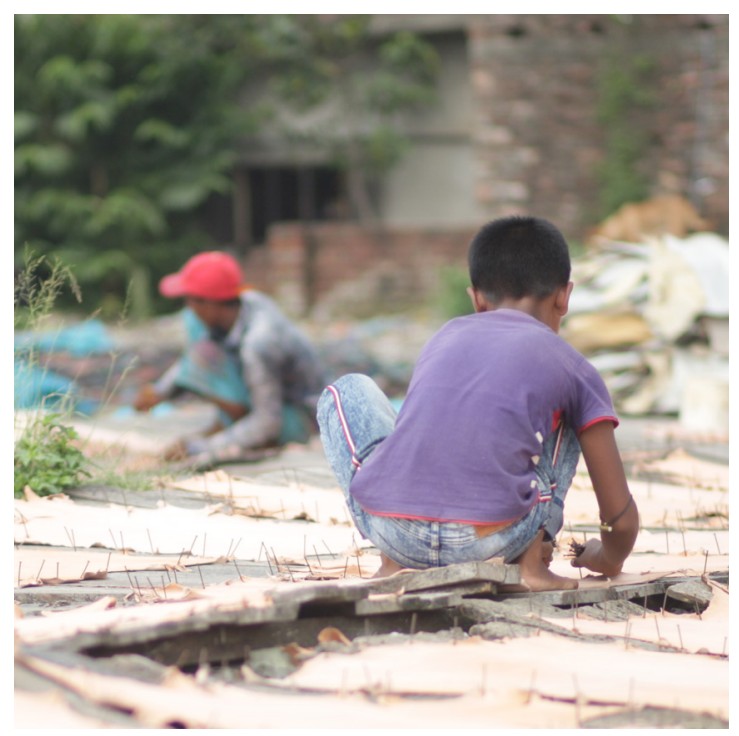

Children are hammering pins on raw leather to dry them under direct sunlight. Credit: Mahmudul Hoque Moni

The mapping includes the experiences of 153 children engaged in the leather industry who have been asked to describe their working conditions, the types of work they perform, the risks they face and how (cont...) 


\section{CASE STUDY: BATING RAW HIDE}

Tofazzel*, aged 15, works at the Savar Tannery Industrial Estate in Hemayetput on the outskirts of Dhaka. His job is to 'bate' hides in order to make them pliable and ready for the tanning process. Tofazzel mixes different types of chemicals into a big drum before adding the hide. He rotates the drum for five minutes every hour. It takes six hours to complete the process.

* Not his real name. All the children interviewed were given pseudonyms to protect their identity.

they are coping with day-to-day struggles including those arising from the COVID-19 pandemic.

The mapping finds evidence of the WFCL in over 100 processes along the supply chain from animal slaughter and flaying to the tanning process and the manufacturing of leather products. As well as exposure to dangerous chemicals, hot sunshine and working with heavy machinery and cutting tools, children along the chain also face long hours and time away from their families. Most of the children in the study work between 12-14 hours a day, six days a week - some even longer - and almost all the children are not in education.

The mapping also finds that over half of the children work because of economic hardship in their household. Hunger is quoted as a prime driver and while many of the children are able to list a long list of the risks involved they feel they have no option but to continue. A dislike of school and a lack of better alternatives are also cited.

Lockdown in the early days of the pandemic became a struggle for survival as almost all the factories closed and workers became jobless. While some factories provided basic food supplies for their workers after the factories closed, only two per cent had access to food support programmes. None of the children interviewed know about child rights. Local industry associations interviewed insist that their businesses are strictly regulated and that the WFCL does not exist in their sector. During the mapping, the researchers witnessed many cases of coercion and the physical and psychological abuse of children.

\section{Clarissa}

The Child Labour: Action-ResearchInnovation in South and South-Eastern Asia (CLARISSA) is a consortium of organisations committed to building a participatory evidence base and generating innovative solutions to the worst forms of child labour in Bangladesh, Myanmar, and Nepal.

\u clarissa@ids.ac.uk

https://clarissa.global

\#ChildLabourAction

\section{LOOKING FORWARD}

This evidence serves as a reminder that the leather supply chain is highly complex as are the reasons why children engage in the WFCL. For instance: it is not only unscrupulous employees that are drawing children into the WFCL but families running small businesses that depend on cheap labour to sustain their livelihoods.

CLARISSA believes that by adopting a participatory, adaptive and child-centred approach through which children and others can develop interventions themselves, tackling the WFCL can be achieved sustainably and at scale.

\section{FURTHER READING}

Afroze, J. (2020) Protecting Child Workers During the Pandemic, Project Syndicate, 24 November 2020

Apgar, M. and Snijder, M. (2020)

Our Best-Evidenced Guess of How We Will Achieve Change, CLARISSA blog, 22 July

Child Labour: Action-Research-Innovation in South and South-Eastern Asia (2021)

Maksud. A.K.M. Khandaker, R.H.; Sayed, S. and Arulanantham, A. (2020) Mapping of Children Engaged in Worst Forms of Child Labour and Modern Slavery in the Supply Chain of Leather Industry in Bangladesh, Brighton: CLARISSA

\section{CREDITS}

This Spotlight Story was written by Clare Gorman (Alburnum Associates) with input from A.K.M. Maksud (Director of Grambangla Unnayan Committee and CLARISSA Technical expert) and edited by Vivienne Benson, CLARISSA Communications Lead.

DOI: 10.19088/CLARISSA.2021.001

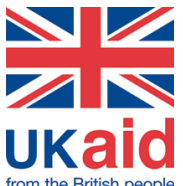

This report has been funded with UK aid from the UK government (Foreign, Commonwealth \& ( The opinions expressed are those of the author and do not necessarily reflect the views or policies of IDS or the UK government.

\section{from the British people}

(c) Institute of Development Studies 2021. This is an Open Access paper distributed under the terms of the Creative Commons Attribution 4.0 International licence (CC BY), which permits unrestricted use, distribution, and reproduction in any medium, provided the original authors and source are credited and any modifications or adaptations are indicated. 